are formed in response to vaccination and the specificity of the response greatly limit the usefulness of vaccines for the protection of close contacts of cases of meningococcal meningitis. High costs of vaccine production and distribution and the instability of group A vaccine at ambient temperatures add further difficulties. Clearly, there is a need and room for further vaccines, as is implicit in the recent call made by a World Health Organisation Study Group for urgent development of effective tools for the control of the disease. ${ }^{29}$

${ }^{1}$ Easton, D M, et al, British Medical fournal, 1974, 1, 507.

2 Cahalane, S F, and Waters, M, Lancet, 1975, 2, 120.

3 British Medical fournal, 1976, 1, 466.

4 Office of Population Censuses and Surveys, Registrar General's Weekly Return for England and Wales, Reference WR 76/4. London, HMSO.

5 Wiggins, G L, Hollis, D G, and Weaver, R, American fournal of Public Health, 1973, 63, 59 .

${ }^{6}$ Fraser, P K, et al, Lancet, 1973, 1, 1235.

7 Artenstein, M S, Schneider, H, and Tingley, M D, Bulletin of the World Health Organisation, 1971, 45, 275.

${ }^{8}$ Surveillance Summary-Meningococcal Disease, Morbidity and Mortality Weekly Report, 1973, 22, 58.

${ }^{9}$ De Morais, J S, et al, Fournal of Infectious Diseases, 1974, 129, 568.

${ }_{10}$ Erwa, H H, et al, Bulletin of the World Health Organisation, 1973, 49, 301.

11 Wahdan, M H, et al, Bulletin of the World Health Organisation, 1973, 48, 667.

12 Mäkelä, P H, et al, Lancet, 1975, 2, 883.

13 Pan American Health Organisation, Morbidity and Mortality Weekly Report, 1974, 23, 349.

14 Goldschneider, I, Gotschlich, E C, and Artenstein, M S, fournal of Experimental Medicine, 1969, 129, 1327.

${ }^{15}$ Reller, L B, MacGregor, R R, and Beaty, H N, fournal of Infectious Diseases, 1973, 127, 56.

${ }^{16}$ Groover, R V, Sutherland, J M, and Landing, B H, New England fournal of Medicine, 1961, 264, 1115.

17 Goldschneider, I, Gotschlich, E C, and Artenstein, M S, Fournal of Experimental Medicine, 1969, 129, 1307.

18 Artenstein, M S, et al, fournal of Infectious Diseases, 1971, 124, 277.

19 Gotschlich, E C, Liu, T Y, and Artenstein, M S, fournal of Experimental Medicine, 1969, 129, 1349.

${ }^{20}$ Gotschlich, E C, Goldschneider, I, and Artenstein, M S, fournal of Experimental Medicine, 1969, 129, 1367.

21 Gotschlich, E C, Goldschneider, I, and Artenstein, M S, fournal of Experimental Medicine, 1969, 129, 1385.

22 Artenstein, M S, et al, fournal of Infectious Diseases, 1970, 121, 372.

23 Artenstein, M S, et al, New England fournal of Medicine, 1970, 282, 417.

24 Gold, R, and Artenstein, M S, Bulletin of the World Health Organisation, $1971,45,279$.

25 Artenstein, M S, et al, Military Medicine, 1974, 139, 91.

${ }^{26}$ Brandt, B L, and Artenstein, M S, Fournal of Infectious Diseases, 1975, 131, S69.

27 Public Health Service, Advisory Committee on Immunisation Practices, Morbidity and Mortality Weekly Report, 1975, 24, 381.

28 Smilack, J D, Annals of Internal Medicine, 1974, 81, 740.

29 World Health Organisation, Press Release WHO 37, 5 November 1975.

\section{Puerperal mastitis}

Breast-feeding seems to be returning to fashion and is being recommended ${ }^{1}$ by the DHSS, yet even so less than half of all new mothers elect to breast-feed..$^{2-4}$ As many as $9 \%$ of these young women may develop puerperal mastitis, ${ }^{5} 6$ and, while some authorities state that weaning is never necessary, ${ }^{7}$ others recommend it. ${ }^{8}$ In all cases, however, the mastitis is painful and distressing. So how can it be prevented?

Sporadic and epidemic forms of puerperal mastitis are recognised. In sporadic mastitis the nipple is fissured and milk stagnates, ${ }^{9}$ representing the end result of poor nursing technique. ${ }^{7}$ Engorgement of the breast prevents the infant drawing both the nipple and the adjacent areola into its mouth: the nipple can only be nibbled and may be damaged, complete drainage of the breast is not achieved, and the scene is set for infection. At first any cellulitis is confined to the interlobular connective tissue, so that it is rare for pus to be expressed from the nipple. ${ }^{10}$ The sequence of events can be prevented by the simple expedient of manually expressing a little milk immediately before nursing to reduce the tension in the breast.? Normal suckling and a strong "let-down" will then complete breast emptying without injury to the nipple.

Epidemic mastitis is a primary duct infection caused by highly virulent strains of Staphylococcus aureus, often now penicillin-resistant. ${ }^{910}$ Pus can always be expressed from the nipple and organisms cultured from the milk. Epidemiological studies have shown that the newborn baby's nasopharynx is the reservoir from which infection is transferred to the mother. ${ }^{11} 12$ The chain of infection is nursery-infant-mother and is initiated by cross-infection, indicating poor nursery asepsis. In an epidemic reported by Ravenholt et al ${ }^{13}$ staphylococcal disease was completely eliminated when temporary closure of the nursery "removed the handle from the pump.'

What is the correct management of a mother who develops puerperal mastitis? The principles governing treatment, clearly defined by Taylor and Way, ${ }^{14}$ are emptying of the breast and control of infection. The breast can be emptied either by suckling or manual expression. There is no place for "resting the inflamed part," as this simply encourages engorgement. Applebaum ${ }^{7}$ advises more frequent nursing in the early stages of the disease, a view supported by numerous reports. 91415 Despite the presence of staphylococcal pyolactia no illness was recorded in any infant in these series. Even established sporadic mastitis need not interrupt lactation, but it is usually advisable to stop nursing with the epidemic form, ${ }^{9}$ since otherwise there is likely to be continued reinfection from the infant's nasopharynx.

Abscess formation occurs in $5-11 \%$ of patients with mastitis $^{915}$ and is a definite contraindication to suckling, though feeding may continue at the contralateral breast. The potential dangers of attempting to suppress lactation with stilboestrol prevent its use in mastitis, ${ }^{16}$ and in any case continued lactation produces speedier resolution. Indeed, inhibition of lactation by stilboestrol is associated with a higher incidence of recurrent abscess ${ }^{17}$; but bromocriptine may prove to be the drug of choice when lactation has to be suppressed. ${ }^{18}$ Encouraging reports from China on the value of extracts from the plant genus Gleditschia warrant further investigation. ${ }^{19}$

The second principle, control of infection, is achieved with antibiotics. Penicillin, given early in an attack, used to produce rapid resolution of puerperal mastitis 11 with a reduction in the incidence of breast abscess. ${ }^{20}$ Flucloxacillin has now become the antibiotic of choice since the emergence of penicillin-resistant strains. ${ }^{21}$ The early use of antibiotics is vital: breast abscess is a common sequel in patients left untreated longer than twenty-four hours. ${ }^{15}$ Delay may result in the development of the "non-tender mass simulating a carcinoma," once mistakenly thought by surgeons to represent antibiotic abuse. ${ }^{22}$ If there is an established breast abscess, however, antibiotics simply delay the inevitable need for drainage, best accomplished by the primary suture technique of Goodman and Benson. ${ }^{16}$

An ounce of prevention is worth a pound of cure. ${ }^{7}$ Sporadic mastitis may be prevented by teaching women a good nursing technique, while control of cross-infection will eliminate the epidemic form. When prevention fails the subclinical stage of lactational mastitis may be recognised cytologically and arrested by oxytocin. ${ }^{23}$ Development of the overt disease requires immediate antibiotic therapy, together with continued breast emptying, ideally by suckling. Lactation need not be suppressed except in epidemics resulting from highly 
virulent infections. At a time when more mothers should be encouraged to breast-feed their babies ${ }^{4}$ they should not lightly be advised to stop nursing at the first sign of infection.

${ }^{1}$ Department of Health and Social Security Report on Present-Day Practice in Infant Feeding. London, HMSO, 1974.

Prothero, R, Medical Officer, 1969, 121, 141

3 Sleigh, G, and Ounsted, M, Lancet, 1975, 1, 753.

Sloper, K, McKean, L, and Baum, J D, Archives of Disease in Childhood, 1975, 50, 165.

5 Jeffrey, J S, Edinburgh Medical fournal, 1947, 54, 442

${ }^{6}$ Fulton, A A, British Medical fournal, 1945, 1, 693.

7 Applebaum, R M, Pediatric Clinics of North America, 1970, 17, 203.

${ }^{8}$ Vorherr, H, fournal of the American Medical Association, 1974, 227, 676.

9 Marshall, B R, Hepper, J K, and Zirbel, C C, Fournal of the American Medical Association, 1975, 233, 1377.

10 Gibberd, G F, American Fournal of Obstetrics and Gynecology, 1953, 65, 1038.

${ }^{11}$ Duncan, J T, and Walker, J, fournal of Hygiene, 1942, 42, 474.

12 Colbeck, J C, Canadian Medical Association fournal, 1949, 61, 557.

${ }^{13}$ Ravenholt, R T, Wright, P, and Mulhern, M, New England fournal of Medicine, 1957, 257, 789

14 Taylor, M D, and Way, S, British Medical fournal, 1946, 2, 731.

${ }^{15}$ Devereux, W P, American Fournal of Obstetrics and Gynecology, 1970, $108,78$.

16 Goodman, M A, and Benson, E A, Medical fournal of Australia, 1970, 1, 1034.

17 Walsh, A, Lancet, 1949, 2, 635.

18 Varga, L, et al, British Medical fournal, 1972, 2, 743.

9 Huai-Chin, H, Chinese Medical fournal, 1973, 11, 152.

20 Newton, M, and Newton, N R, Surgery, Gynecology and Obstetrics, 1950, 91, 651.

21 Bates, T, et al, Practitioner, 1973, 211, 541.

22. Stammers, F A R, British Medical fournal, 1953, 1, 272.

23 Vanina, L V, and Chumak, T F, Akusherstvo i Ginekologiia (Moskva), 1973, 49, 48.

\section{When should regular dialysis therapy start?}

For most dialysis units the time of starting patients with chronic uraemia on regular dialysis is decided by logistics rather than a precise knowledge and control of the factors determining the best time. There can be few nephrologists who have not been obliged to practise the art of brinkmanship as they have tried to fit the queue of patients with progressive end-stage renal failure into the barely adequate, or in some cases inadequate, facilities at their disposal. Without doubt in the past many patients were too uraemic for too long and had of necessity existed on a severely restricted protein intake before a place could be found for them on a dialysis programme. Neither survival nor rehabilitation could be optimal in such circumstances.

Precise information about when nephrologists start their patients on regular dialysis therapy is not easy to come by. In most British units, as elsewhere, patients generally seem to start dialysis when the creatinine clearance is beginning to fall below $5 \mathrm{ml}$ min at a time when clinical manifestations of uraemia are becoming more troublesome for the patient. Often, however, the clinician has no choice in the matter; he first sees the patient in far advanced end-stage renal failure in circumstances where there is little scope for manoeuvre. In all cases before a final decision is taken to begin dialysis the nephrologist will have looked for, and corrected if possible, the presence of any reversible factors such as salt or water depletion, severe hypertension, obstruction within the urinary tract, analgesic abuse, and renal and systemic infection.

Bonomini and his colleagues ${ }^{1}$ have recently put forward the provocative suggestion that we are still not doing well enough for our patients by delaying the start of regular dialysis therapy until the creatinine clearance has fallen to around or below
$5 \mathrm{ml} / \mathrm{min}$. In a retrospective analysis of about 150 patients they compared the outcome in those who started dialysis when the creatinine clearance had fallen to between 0 and $5 \mathrm{ml} / \mathrm{min}$, those with clearances of $5-15 \mathrm{ml} / \mathrm{min}$, and those with clearances at the start of dialysis of between $15-21 \mathrm{ml} / \mathrm{min}$. They concluded that the patients who started dialysis with the highest residual creatinine clearances did best, in terms of both survival and rehabilitation. This is perhaps a not surprising conclusion, since clearly the benefits of a residual renal function of, say, $15 \mathrm{ml} / \mathrm{min}$ will almost invariably mean one is dealing with a fitter group of patients. Furthermore, such patients will not have the same problems of fluid restriction, sodium restriction, and potassium restriction that must be faced by the severely oliguric or anuric individual with negligible renal function.

The Italian study is open to criticism: it has some of the defects associated with all retrospective analyses, and the dialysis schedules in the different groups of patients were not identical. It is even more likely to invite criticism because of the formidable logistic problem that adoption of its conclusions would inevitably bring, particularly when there is no room in most countries for complacency with the number of patients with end-stage renal failure who receive treatment by dialysis or transplantation. Study of the data ${ }^{2}$ of the registration committee of the European Dialysis and Transplant Association for the year ending 1973 showed that the United Kingdom was about middle of the league table, providing treatment for 46 patients per million of the population compared with the Danish figure of 104. Nevertheless, the argument that regular dialysis therapy should be started at an earlier stage than is the general practice throughout the world, though not necessarily as early as Bonomini advocates, should not be dismissed out of hand. Starting of dialysis at creatinine clearance values somewhat above $5 \mathrm{ml}$ min rather than distinctly below that level would undoubtedly mean a smoother start to treatment and a lower incidence of complications for most patients. Unfortunately, hard realities make such a policy a luxury that few countries will be able to indulge in.

\footnotetext{
${ }^{1}$ Bonomini, V, et al, Nephron, 1976, 16, 89.

2 Parsons, F M, et al, in Dialysis, transplantation, nephrology: Proceedings of the European Dialysis and Transplant Association, II, ed J F Moorhead. London, Pitman, 1974.
}

\section{Pancreatic pain}

Pain arising from a diseased pancreas may be both severe and very persistent. At times it is quite crippling, and its management presents a difficult problem which can test the ingenuity of the treating physician. The exact mechanism of the pain is not clearly understood, but it may arise either because of partial or complete blockage of the pancreatic duct, leading to distension, or because of inflammation of the peripancreatic nerves or their infiltration by malignant tissue. The afferent pathway from the pancreas passes to the coeliac plexus and then via the right and left splanchnic nerves to the right and left 6-11th sympathetic ganglia. There is some lateralisation of distribution-most fibres from the head of the gland pass to the right side and most from the tail to the left-but this separation is not absolute. ${ }^{1}$

Chronic upper abdominal pain cannot certainly be attributed to pancreatic disease short of a laparotomy, but in most cases it can be identified as pancreatic because it is constant and 